\title{
Temperament profiles are associated with dietary behavior from childhood to adulthood
}

\section{Lipsanen, Jari}

2020-08-01

Lipsanen , J , Elovainio , M , Hakulinen , C , Tremblay , M S , Rovio , S , Lagström , H , Jaakkola , J M , Jula , A, Rönnemaa , T, Viikari , J, Niinikoski , H, Simell , O, Raitakari , O T , Pahkala , K \& Pulkki-Råback , L 2020 , ' Temperament profiles are associated with dietary behavior from childhood to adulthood ' , Appetite , vol. 151 , 104681 . https://doi.org/10.1016/j.appet.2020.10

http://hdl.handle.net/10138/328676

https://doi.org/10.1016/j.appet.2020.104681

cc_by_nc_nd

acceptedVersion

Downloaded from Helda, University of Helsinki institutional repository.

This is an electronic reprint of the original article.

This reprint may differ from the original in pagination and typographic detail.

Please cite the original version. 


\section{Journal Pre-proof}

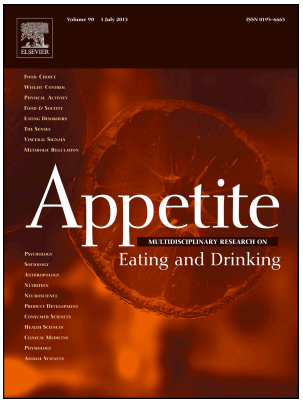

Temperament profiles are associated with dietary behavior from childhood to adulthood

Jari Lipsanen, Marko Elovainio, Christian Hakulinen, Mark S. Tremblay, Suvi Rovio, Hanna Lagström, Johanna M. Jaakkola, Antti Jula, Tapani Rönnemaa, Jorma Viikari, Harri Niinikoski, Olli Simell, Olli T. Raitakari, Katja Pahkala, Laura Pulkki-Råback

PII: S0195-6663(19)30782-2

DOI: https://doi.org/10.1016/j.appet.2020.104681

Reference: APPET 104681

To appear in: Appetite

Received Date: 4 July 2019

Revised Date: 1 March 2020

Accepted Date: 21 March 2020

Please cite this article as: Lipsanen J., Elovainio M., Hakulinen C., Tremblay M.S., Rovio S., Lagström H., Jaakkola J.M., Jula A., Rönnemaa T., Viikari J., Niinikoski H., Simell O., Raitakari O.T., Pahkala K. \& Pulkki-Råback L., Temperament profiles are associated with dietary behavior from childhood to adulthood, Appetite (2020), doi: https://doi.org/10.1016/j.appet.2020.104681.

This is a PDF file of an article that has undergone enhancements after acceptance, such as the addition of a cover page and metadata, and formatting for readability, but it is not yet the definitive version of record. This version will undergo additional copyediting, typesetting and review before it is published in its final form, but we are providing this version to give early visibility of the article. Please note that, during the production process, errors may be discovered which could affect the content, and all legal disclaimers that apply to the journal pertain.

(C) 2020 Published by Elsevier Ltd. 
ABSTRACT

Background and objectives: Temperament may be associated with eating behaviors over the lifespan. This study examined the association of toddlerhood temperament with dietary behavior and dietary intervention outcomes across 18 years.

Methods: The study comprised 660 children (52\% boys) from The Special Turku Intervention Project (STRIP), which is a longitudinal randomized controlled trial from the age of 7 months until the age of 20 years (1990-2010). Temperament was assessed using Carey temperament scales when the participants were 2 years of age. Latent profile analysis yielded three temperament groups, which were called negative/low regulation (19\% of the children), neutral/average regulation (52\%) and positive/high regulation (28\%). Dietary behavior was examined from 2 to 20 years of age using food records, which were converted into a diet score (mean=15.7, SD 4.6). Mixed random-intercept growth curve analysis was the main analytic method.

Results: Dietary behavior showed a significant quadratic U-shaped curve over time (B for quadratic association=0.39, $P<.001$; B for linear association=0.09, $\mathrm{P}=0.58$ ). Children in the negative/low regulation temperament group had a lower diet score (less healthy diet) across the 18 years compared to children in the neutral/average or in the positive/high regulation group. Temperament was not associated with the rate of change in diet over time. Temperament did not have any interactive effects with the intervention $(\mathrm{F}[2,627], P=0.72)$.

Conclusion: Children with a temperament profile characterized by high negative mood, high irregularity and high intensity in emotion expression constitute a risk group for less healthy eating over the lifespan.

Keywords: Temperament, dietary behavior, longitudinal study, intervention 


\title{
Temperament profiles are associated with dietary behavior from childhood to adulthood.
}

Jari Lipsanen, MA, ${ }^{1}$ Marko Elovainio, $\mathrm{PhD},{ }^{1,2}$ Christian Hakulinen, $\mathrm{PhD},{ }^{1}$ Mark S. Tremblay, $\mathrm{PhD}^{3}$, Suvi Rovio, $\mathrm{PhD},{ }^{4}$ Hanna Lagström, $\mathrm{PhD},{ }^{5}$ Johanna M. Jaakkola, $\mathrm{PhD},{ }^{4}$ Antti Jula, $\mathrm{MD}, \mathrm{PhD},{ }^{2}$ Tapani Rönnemaa, MD,${ }^{6}$ Jorma Viikari, MD,${ }^{6}$ Harri Niinikoski, MD, ${ }^{7}$ Olli Simell, MD, ${ }^{6}$ Olli T. Raitakari, MD, ${ }^{4,8,9}$ Katja Pahkala, PhD $^{4,10^{*}}$ Laura Pulkki-Råback ${ }^{1,11^{*}}$

*Shared last authorship for K.P. and L.P.-R.

\author{
Affiliations: \\ ${ }^{1}$ Department of Psychology and Logopedics, Faculty of Medicine, University of Helsinki, \\ Finland \\ ${ }^{2}$ National Institute for Health and Welfare, Finland \\ ${ }^{3}$ Healthy Active living and Obesity Research Group, CHEO Research Institute, Ottawa, \\ Canada \\ ${ }^{4}$ Research Centre of Applied and Preventive Cardiovascular Medicine, University of Turku, \\ Finland \\ ${ }^{5}$ Department of Public Health, University of Turku, and Turku University Hospital, Turku, \\ Finland \\ ${ }^{6}$ Department of Medicine, University of Turku and Division of Medicine, Turku University \\ Hospital, Finland \\ ${ }^{7}$ Institute of Biomedicine, University of Turku, and Department of Pediatrics and Adoles- \\ centMedicine, Turku University Hospital, Turku, Finland \\ ${ }^{8}$ Centre for Population Health Research, University of Turku and Turku University Hospital \\ ${ }^{9}$ Department of Clinical Physiology and Nuclear Medicine, Turku University Hospital, \\ Finland \\ ${ }^{10}$ Paavo Nurmi Centre, Sports \& Exercise Medicine Unit, Department of Health and Physical \\ Activity, University of Turku, Finland \\ ${ }^{11}$ Research Centre for Child Psychiatry, Faculty of Medicine, University of Turku, Finland
}

Address correspondence to: Laura Pulkki-Råback, Department of Psychology and Logopedics, Faculty of Medicine, Haartmanninkatu 3 (P.O. Box 21), 00014 University of Helsinki, Finland. E-mail:laura.pulkki-raback@helsinki.fi, tel. +358 505367256.

Financial disclosures: Hanna Lagström participated as an advisory board member, consultant, and speaker for Nestlé Nutrition Institute and Nestlé Finland. Other authors have indicated they have no financial relationships relevant to this article to disclose.

Conflict of interest statement: The authors have no conflicts of interest.

Clinical trial registration: www.clinicaltrials.gov, Identifier: NCT00223600, register title: Special Turku Atherosclerosis Risk Factor Intervention Project for Children (STRIP).

Data sharing statement: Selected variables and their descriptions without personal identification codes are distributed to investigators and collaborators working on specific projects. The rights to the data belong to the STRIP research group. Data sharing outside the STRIP group requires a data-sharing agreement. Investigators can submit an expression of interest to the STRIP Steering Committee by contacting the corresponding author. 


\section{INTRODUCTION}

The health-burden of children and young people eating energy-dense foods with low nutritional value is substantial. ${ }^{1,2}$ Researchers have recently suggested that dietary interventions should be tailored according to individual characteristics, because the same treatment may not be equally effective for all people. ${ }^{3-6}$ Currently, there is relatively little information about individual characteristics that may predict dietary behavior and intervention outcomes over the lifespan.

Childhood temperament is an individual characteristic to consider in dietary behavior, as it has been associated with health behaviors and health outcomes later in life..$^{3,7-9}$ Temperament refers to early emerging behavioral dispositions in the domains of activity, affectivity, attention and self-regulation that are relatively stable over the lifespan and that form the core of later personality. ${ }^{10-12}$ Research has shown that temperament domains including high negative affect (easily aroused distress) and low self-regulation (difficulty in controlling behavior) are associated with unhealthier overall diets, ${ }^{13-15}$ higher consumption of sweet foods, ${ }^{16-18}$ eating more snack foods, ${ }^{19,20}$ eating foods with a higher calorie content, ${ }^{21}$ skipping breakfast ${ }^{22}$ and not eating recommended amounts of fruits and vegetables. ${ }^{19}$ While these studies show a rather consistent association between temperament and dietary behavior, the findings are limited to the childhood or adolescence period and longer follow-up studies are lacking.

Previous studies have focused on the role of specific temperament traits in relation to dietary outcomes. Focusing on separate traits does not reflect the fact that behavior results from combinations of traits within each individual. ${ }^{23-25}$ A person-centered perspective to temperament considers the organization of traits within individuals as the unit of analysis, and this approach is becoming increasingly common in personality research. ${ }^{26}$ Latent profile 
analysis is a person-centered statistical method that allows differentiating groups of children who share similar combinations of temperament attributes. ${ }^{27}$ Previous studies using personcentered approaches have shown that infants and toddlers often fall into three or four temperament groups, sometimes called profiles. ${ }^{24-26}$ Profiles have the advantage of capturing different underlying biological processe ${ }^{23,28}$ and they enable more accurate prediction of various developmental outcomes. ${ }^{26}$ One purpose of this study was to examine whether temperament profiles are associated with dietary behavior spanning childhood, adolescence and early adulthood.

Pertaining to the question of personalizing interventions, temperament has been suggested to act as a modifier of intervention outcomes..$^{3-5,29,30}$ The differential susceptibility hypothesis $^{31}$ suggests that children vary in their behavioral responses to environmental stimuli according to their inborn characteristics (such as temperament), leading to a possibility that children with various temperaments may respond differently to the same intervention. ${ }^{3-5,29,30}$ An obesity prevention study showed that fussy infants (high in negative affect) benefitted more than easier infants from a maternal feeding-intervention, ${ }^{32}$ while another study found that highly sociable children benefitted most from a 14-day dietary intervention. ${ }^{33}$ These studies suggest that temperament may be associated with intervention outcomes, but evidence remains inconclusive.

We examined in longitudinal data collected over 18 years (1) whether temperament profiles in toddlerhood are associated with dietary behaviors in childhood, adolescence, and early adulthood, and (2) whether the effect of a long-term dietary intervention differs by temperament profiles, that is, whether it is possible to identify groups of children who are especially responsive to dietary interventions. 


\section{MATERIAL AND METHODS}

\section{Participants and Study Design}

The participants are from the Special Turku Intervention Study (STRIP), a randomized controlled trial to promote heart-healthy eating during childhood and adolescence. ${ }^{34}$ The trial has demonstrated beneficial effects on the heart health of the children. ${ }^{35-37}$ The study recruited all 5-month-old children in Turku, Finland. At the age of 7 months (March 1990 - May 1992), 1062 children (57\% of the entire age cohort) were randomly allocated to a dietary intervention $(n=540)$ or a control $(n=522)$ group. The intervention group received dietary counselling every 6 months over 20 years. There were 898 participants who gave temperament data at the age of 2 years ( $85 \%$ of the study group) and of them, 660 participants had data on the covariates and at least one dietary measurement (326 children in the intervention group and 334 children in the control group; supplement figure 1 for a flow diagram). Comparing the 660 children with the original sample $(\mathrm{N}=1,062)$ showed that there were no differences pertaining to sex $(P=0.917)$, belonging to the intervention group $(P=0.982)$ or maternal $(P=0.469)$ and paternal $(P=0.689)$ education. All participants gave informed consent. The work was approved by local ethics committees, has been carried out in accordance with The Declaration of Helsinki and it confirms to Recommendations for the Conduct, Reporting, Editing and Publication of Scholarly Work in Medical Journals.

\section{Measurement of temperament}


Temperament was assessed at 2 years of age using the Toddler Temperament Scales, which is a caregiver report questionnaire belonging to the Carey Temperament Scales. ${ }^{38}$ It measures nine temperament traits: activity, rhythmicity, approach, adaptability, intensity, mood, persistence, distractibility, and sensory threshold. The questionnaire consists of 97 statements about the child to which the caretaker is asked to assign a value from 1 (almost never true) to 6 (usually true). A higher score indicates a more difficult temperament (e.g., a high rhythmicity score indicates irregular sleeping and eating rhythms) as described in Table $\mathbf{1 .}$ The scale has been shown to have acceptable internal consistency on most dimensions (alphas in 2-year olds ranged from 0.53 to 0.85 ) and a 1-month test-retest reliability with a median of $0.81 .^{39}$ The scale has been shown to predict conceptually relevant outcomes such as child psychopathology ${ }^{40}$ and maternal ratings on this scale have been shown to correspond to ratings made by independent observers. ${ }^{41}$

We applied latent profile analysis (LPA) to construct temperament groups based on the nine temperament traits. LPA is a person-centred method that describes how traits are organized within individuals by organizing respondents into similar groups, based on statistical combinations of traits. The optimal number of latent classes was estimated based on information criteria's (AIC, AICC, BIC, aBIC) and by using modified likelihood ratio tests. $^{42,43}$ Although information criteria continued to improve when number of latent classes increases, the likelihood ratio test indicated that after a three-class solution the improvement of the model fit was no longer significant, but three class solution was significantly better then two class solution $($ Table 2; BIC $=14031.59$ Entropy $=0.73$, both $P$-values $=<.01$ ) Based on likelihood ratio tests we chose a three-class solution, which also had highest entropy.

Figure 1 depicts the temperament groups (means are in supplement table 1). We named the first group negative/low regulation $(\mathrm{n}=148 ; 19 \%$ of the participants), where 
the word "negative" refers to negative quality of mood and low regulation refers to irregular rhythms and high intensity, suggesting that these children had challenges in regulating their biological rhythms and emotional expressions. The second group was named neutral/average regulation ( $\mathrm{n}=393 ; 52 \%$ of the participants), because it had average values in all traits. The third group was named positive/high regulation $(\mathrm{n}=211 ; 28 \%$ of the participants), because it included children characterized by positive mood, highly regular rhythms, and low intensity, referring to good ability to regulate emotion and biological functions.

\section{Description of the dietary intervention}

The intervention group attended 30-minute sessions led by a nutritionist at 1-3 month intervals until the age of 2 years and every 6 months thereafter until 20 years of age. The dietary recommendations were based on the most recent Nordic Nutrition Recommendations available at the time (e.g., 30 percent of energy intake [E\%] from fat, 10$15 \mathrm{E} \%$ from protein, and 50-60 E\% from carbohydrates). The control group participants were met at 6-month intervals until the age of 7 years and thereafter annually for laboratory examinations.

The dietary counselling targeted heart health and was therefore focused on the replacement of saturated fat with unsaturated fat in the child's diet, and promotion of the intake of vegetables, fruits, and whole-grain products, and reduction of sodium and sucrose intake as secondary targets. ${ }^{34}$ Counselling was family-based and given to the parents until the child was 7 years-old, and thereafter gradually more information was given directly to the child. There was no fixed diet, but instead the child's food 4-day record, which had been sent to the child prior to the visit, was used as a basis of suggestions for dietary changes. For example, the child was taught how to identify high saturated fat foods and how to replace these foods with a more favourable fat composition. Between the study visits, letters 
containing tasks (e.g., drawing tasks depicting healthy foods) and recipes on how to prepare healthy foods were sent as reminders to the participants. All study visits were completed at the Research Centre of Applied and Preventive Cardiovascular Medicine at the University of Turku, Finland.

\section{Dietary data and diet score}

Food consumption was examined using food diaries, ${ }^{44}$ which were kept over 4 consecutive days, of which at least one was a weekend day. When the participants were infants, the parents and/or caregivers were responsible for filling out the food records. After beginning of day-care or school, the personnel (e.g., teachers) were asked to assist the child in completing the food records. As the children aged, they were given more responsibility for completing their food records. Usually this occurred around the age of 12 years, but there was variability between children. The parents were still advised to check the records and assist the child in completing them. The nutritionist reviewed the food records for completeness at every study visit, and if necessary, added missing details after discussing them first with the child and/or the parent. Occasionally, further details were sought from schools or manufacturers. The Micronutrica ${ }^{\circledR}$ software was used to calculate food and nutrient intakes based on the food records. This software is coupled with continuously updated data bank comprising $>4000$ foods and dishes. This vast data bank on single food items and dishes, and the fact that a single dietary technician has analysed all food records, ensures high quality of the dietary data.

Following a multi-cohort study by Nettleton and others ${ }^{45}$ and a study by Matthews and others in this same dataset, ${ }^{46}$ we classified the foods into 11 food groups (Supplement table 2). The food groups were drawn from the evidence-based conclusions of 
the Nordic Nutrition Recommendations and the 2015-2020 Dietary Guidelines for Americans. ${ }^{47}$ Daily intake of foods and beverages were calculated in grams per total energy intake and then classified into quartiles where favourable foods (e.g., vegetables) were given ascending values 0,1,2,3 and unfavourable food (e.g., sugar-sweetened beverages) descending values 3,2,1,0. Because few children consumed nuts/seeds or salty snacks, their consumption was dichotomized as any or no consumption ( 3 vs. 0 points). The 11 food groups were summed together to calculate a diet score where a higher score indicates a healthier diet (range 0-33).

\section{Covariates}

Parents' socioeconomic status and psychological distress may affect feeding practices, which in turn are associated with children's eating behaviors and weight status. ${ }^{4,48}$ Therefore, we adjusted for parental educational level (primary/secondary/tertiary), parental anxiety (20-item Spielberger Trait Anxiety scale), ${ }^{49}$ and the participant's body-mass index (a time-dependent variable over 18 years).

\section{Statistical analyses}

We used longitudinal random-slope growth curve analysis with unstructured error covariance matrix to examine the childhood temperament groups predicting the total diet score from age 2 years until age 20 years. We entered the intervention group $(0=$ control, $1=$ intervention), sex, temperament group, linear time trend, quadratic and cubic time trend, and their threeway and two-way interaction terms, and the main effects of parental educational level, parental anxiety and participant's body-mass index as predictors of the diet score. The full model is shown in Supplement table 3. We first excluded non-significant three-way interactions, then we excluded non-significant two-way interactions and finally we excluded non-significant main effects from the model until only significant predictors were present. 
Statistical significance was assessed using Satterthwaite Approximation and parametric bootstrapping with 1000 bootstrapped resamples. R-software version 3.5 was used in the

analyses. Growth curve models were analysed using lme4 and lmerTest -packages. ${ }^{50,51}$ As additional analyses, we ran growth curve models with the temperament groups predicting each food group at a time. We also ran analyses with the individual temperament traits (9 traits) predicting the diet score over time.

\section{RESULTS}

The descriptive statistics in supplement table 4 show the characteristics of the sample at the age of 2 years and at the age of 20 years. There were no statistically significant differences between the control and the intervention group $(P=0.115)$ in the distribution of the temperament profiles; $26 \%, 57 \%$, and $17 \%$ of the control children and $29 \%, 49 \%$, and $23 \%$ of the intervention children belonged to the negative/low regulation, neutral/average regulation, and positive/high regulation groups, respectively. In line with our previous report $^{46}$ the intervention children had a healthier diet score at the age of 20 years than the control children (means $=17.3$ vs. $15.7, P=0.004)$.

\section{Temperament and dietary behavior}

The result of the final growth curve model is shown in table 3. It explained $46 \%$ of variance in the diet score. The diet score had a quadratic U-shaped trajectory over time (unstandardized beta coefficient for quadratic term $=0.39, P<.001$ ). Linear trend was not significant (undstandardized beta coefficient $=0.09, P=0.58$ ) indicating that there was no significant 
linear increase in diet score over time.

Figure 2 shows that children in the negative/low regulation group had lower (i.e., less healthy) diet scores across the 18 years of follow up compared to children in the neutral/average regulation group or in the positive/high regulation group. There were no interaction effects between temperament and time in predicting the diet score (temperament group $\times$ linear age, $P=0.574$; temperament group $\times$ quadratic age, $P=0.375)$, suggesting that temperament did not predict the rate of change in diet over time. This finding may imply that early temperament is associated with early eating behaviour, which in turn is relatively stable over time. To elaborate on this possibility, we conducted post-hoc tests for pairwise differences of estimated marginal means between temperament groups. The result showed that children in the negative/low regulation temperament group had 0.19 standard deviations lower (unhealthier) diet score at age of $20(P=.012$, False discovery rate corrected $P$-value $=$ 0.04) compared to the positive/high regulation group. This association didn't remain significant after the effect of diet score at age of 2 was controlled $(\mathrm{p}=.75)$. This is expected because we didn't observe interaction effect between age and temperament group.

Examining the individual food groups as continuous outcomes (g/day) (supplement figure 2) showed that children in the negative/low regulation temperament group consumed significantly fewer vegetables, more sugar-sweetened beverages and more desserts across the follow-up period than children in the other temperament groups $(F$ values $=3.45,3.22$, and $2.98, P$-values $=.03, .04$, and .05 , respectively).

When the nine temperament traits were examined separately as predictors of diet, there were associations between high irregularity and lower diet score $(B=-0.56$, $P<0.001)$ and between high intensity and the lower diet score $(B=-0.29, P<0.001$; Table 4).

\section{Testing temperament as a modifier of the intervention}


The growth curve analysis showed no significant interactions between the temperament groups and belonging to the intervention (vs. not) in predicting the diet score over the 18 -year follow-up period $(F[2,627]=0.3296, P=0.72)$. In both the control and the intervention groups, the negative/low regulation temperament profile had the lowest diet score throughout the study phases, indicating no modifying effect of temperament.

\section{DISCUSSION}

Using longitudinal data, we showed that a temperament profile characterized by negative mood, high irregularity, and high intensity was associated with consistently less healthy dietary behavior across 18 years compared to a temperament profile characterized by a more positive mood and better self-regulation. Temperament did not predict changes in eating behavior across time, which suggests that early temperament predicts early eating behavior, which in turn is sustained over time. Previous work has shown an association between temperament traits and dietary behavior ${ }^{13-20,22}$ but to our knowledge, this is the first study to examine the association of temperament profiles on eating behavior over such a long time period.

Following the differential susceptibility hypothesis, we examined if temperament would be modify intervention outcomes. ${ }^{32,33} \mathrm{We}$ found no such result; children with different temperaments did not respond differently to the intervention. It is noteworthy, however, that the intervention was carried out in a one-to-one setting between the dietician and the child. Although not instructed to do so, the counselling personnel may have adjusted 
the intervention according to each child's temperament (e.g., taking time to soothe a distressed child), which could have diminished the impact of temperament. Further, a previous intervention study targeted parental feeding practices, ${ }^{32}$ while the current study targeted specific food selections, suggesting that temperament could play a different role depending on the intervention targets.

It is important to consider the possible mechanisms underlying this "long shadow" of temperament on dietary behavior. ${ }^{9}$ First, parents may feed children differently, depending on the child's temperament. Some ${ }^{14,17,18}$ although not all ${ }^{52}$ studies suggest that parents often attempt to regulate their children's challenging temperaments by giving them comforting foods. Second, children and youth may use foods to comfort themselves and to regulate their own mood. Pertaining to this hypothesis, researchers of the Head Start obesity prevention study examined if teaching preschoolers self-regulation skills would decrease obesity, but there was no reduction in obesity prevalence or most obesity-related behaviors. ${ }^{53}$ Third, genetic and neurobiological factors may be involved. A British study showed that the association between a behavioral trait called "food fussiness" and liking of vegetables and fruit in young children was significantly explained by common genetic factors. ${ }^{54}$ The possible role of genetics in individual differences in dietary behavior is worth studying in the future.

Several limiting factors need to be considered when interpreting the findings. One methodological limitation is loss to follow-up during the 18 -year study period. Although we found no systematic selection, a previous report in this dataset has shown that females and participants with leaner body-mass index were overrepresented in the follow-up samples. ${ }^{55}$ Second, relying on parental perceptions of child temperament may be a limitation, because parental ratings may reflect poorness of fit between the caretaker and the child. We adjusted the analyses for parental educational level and parental psychological anxiety level, but we 
were unable to adjust for parental feeding practices that may have a significant explaining role in the association between child's temperament and dietary outcomes. ${ }^{48}$

Although dietary behavior was obtained using a well-established method (4-day food diary), it is subject to the same limitations as any self-report measure, including social desirability and accuracy issues. In future studies, it would be important to examine if the results replicate using more objective measures of dietary behavior. Another limitation is that between ages 10 and 14 the reporter was either the parent or the child, which may introduce variability in reporter's cognitive level as well as the extent to which the reporter was present at all meals.

The Carey temperament scales are derived from the classic New York Longitudinal Studies (NYLS), where Thomas and Chess identified difficult, slow-to-warm up, and easy temperament types in children. ${ }^{11}$ Difficult temperament as described by Thomas and Chess $^{39}$ refers to children who have high negative mood, are slow to adapt, are very intense and have irregular functions (e.g., sleep). Our study yielded a negative/low regulation group which had several common characteristics with the difficult temperament description (high negative mood, high intensity and low regularity). In contrast, the easy temperament pattern by Thomas and Chess describes children who are adaptable, positive, regular, and moderate in their emotional reactions. ${ }^{11,39}$ We found a similar group that we named positive/high regulation (characterized by a predominant positive mood, regular rhythms, and low intensity of emotional expression). We did not however replicate the "slow to warm up" group, which according to Thomas and Chess refers to children who are passive, withdrawn and slow to adapt. ${ }^{11}$ Instead, we found an "average" group of children with medium levels in all characteristics. Thus, our study replicated the Thomas and Chess profiles to some degree but not entirely.

The Carey Scales are based on clinical observations without any hypotheses 
about the physiological origins of temperament. Recent studies suggest that temperamental emotion regulation in infancy and toddlerhood is based on maturational shifts in autonomic regulation, and specifically to the myelination of the vagus system, which coordinates basic behaviors such as sleeping, feeding, arousal, and sensory difficulties. ${ }^{56}$ We had no data on autonomic cardiac profiles, but a previous study using the Carey Scales showed that children rated as "difficult" (negative mood, poor regulation) had slower heart rates and greater heart rate variability compared to children rated as easy. ${ }^{41}$ For instance, children with low sympathetic tone may may be better able to receive the information presented in interventions because they are not experiencing high sympathetic or high parasympathetic discharge. To examine these possibilities, future studies should examine autonomic nervous system functioning in relation to temperament and dietary behaviour.

Finally, the limitations of the Latent Profile Analysis should be addressed. This method can be criticized because it can produce different results in different datasets. While some studies have found as many as six temperament groups among chldren, ${ }^{27}$ several studies have shown that three or four groups is an optimal solution for distinguishing temperament profiles in infants or toddlers. ${ }^{24-26}$ A Dutch study found a three-profile model to have best fit with data in toddlers ${ }^{27}$ while the Early Growth and Development Study found four profiles of temperament to have best fit the data. ${ }^{25} \mathrm{~A}$ common finding across studies (including our study) is that they distinguish between a more "negative" temperament group (negative affect and low regulation) and a "positive" group (positive affect and high regulation). In our study, about one third belonged to the positive/high regulation group while one fifth belonged to the negative/low regulation group, which coincides very well with a recent British study. ${ }^{57}$

A notable strength of this study is its uniquely long dietary intervention from toddlerhood to early adulthood. It is rare to have records of dietary behavior over this extended developmental period. Second, the dietary intervention was given by a trained 
nutritionist at individual sessions and included the family, which is a recommended method for lifestyle interventions. ${ }^{44}$ Third, the sample represented an entire age cohort from a geographical area, which is different from many studies focusing on selected risk groups. If primary prevention aims to shift the distribution of the entire population, it is important to conduct assessments over the entire spectrum of children.

In conclusion, temperament profiles were associated with dietary behavior over almost two decades, but temperament did not modify the effect of the dietary intervention. Toddlers high in negative mood, irregularity, and intense emotion expression are at higher risk for choosing less healthy foods, and clinicians as well as parents should be aware of this when aiming to promote healthy eating in children.

\section{ACKNOWLEDGEMENTS}

The data management expertise of Noora Kartiosuo and Irina Lisinen is greatly appreciated.

\section{FUNDING SOURCES}

This work was supported by the Academy of Finland (grants 310591 [C.H.], 206374, 294834, 251360, and 275595, 307996, 322112), the Academy of Finland Flagship Programme (INVEST Research Flagship, decision number: 320162), the Juho Vainio Foundation, the Finnish Foundation for Cardiovascular Research, the Finnish Ministry of Education and Culture, the Finnish Cultural Foundation, the Sigrid Jusélius Foundation, Special Governmental grants for Health Sciences Research (Turku University Hospital), the Yrjö Jahnsson Foundation, the Finnish Medical Foundation , the Turku University Foundation, and the Jenny and Antti Wihuri Foundation. The funders have no role in the collection, analysis, or interpretation of the data, or in writing of the manuscript or in decisions to publish the report. 


\section{REFERENCES}

1. Banfield EC, Liu Y, Davis JS, Chang S, Frazier-Wood AC. Poor Adherence to US Dietary Guidelines for Children and Adolescents in the National Health and Nutrition Examination Survey Population. J Acad Nutr Diet. 2016;116:21-27.

2. NCD Risk Factor Collaboration (NCD-RisC). Worldwide trends in body-mass index, underweight, overweight, and obesity from 1975 to 2016: a pooled analysis of 2416 population-based measurement studies in 128.9 million children, adolescents, and adults. Lancet. 2017;390:2627-2642.

3. Anzman-Frasca S, Stifter CA, Birch LL. Temperament and childhood obesity risk: A review of the literature. J Dev Behav Pediatr. 2012;33:732-745.

4. Bergmeier H, Skouteris $\mathrm{H}$, Horwood S, Hooley M, Richardson B. Associations between child temperament, maternal feeding practices and child body mass index during the preschool years: a systematic review of the literature. Obes Rev. 2014;15:8-18.

5. Israel S, Moffitt TE, Belsky DW, et al. Translating personality psychology to help personalize preventive medicine for young adult patients. J Pers Soc Psychol. 2014(106):484-498.

6. Lunn TE, Nowson CA, Worsley A, Torres SJ. Does personality affect dietary intake? Nutrition. 2014;30:403-409.

7. Pulkki-Råback L, Elovainio M, Kivimäki M, Raitakari OT, Keltikangas-Järvinen L. Temperament in childhood predicts body mass in adulthood: the Cardiovascular Risk in Young Finns Study. Health Psychol. 2005;24(3):307-315.

8. Caspi A, Begg D, Dickson N, et al. Personality differences predict health-risk behaviors in young adulthood: Evidence from a longitudinal study. J Pers Soc Psychol. 1997;73:10521063.

9. Faith MS, Hittner JB. Shadows of temperament in child eating patterns: implications for family and parenting research. Am J Clin Nutr. 2016;103:961-962. 
10. Shiner RL, Buss KA, McClowry SG, Putnam SP, Saudino KJ, Zentner M. What is temperament now? Assessing progress in temperament research on the twenty-fifth anniversary of Goldsmith et al. (1987). Child Dev Perspect. 2012;6:436-444.

11. Thomas A, Chess S. Temperament and development. New York: Brunner/Mazel; 1977.

12. Rothbart MK, Ahadi SA, Evans DE. Temperament and personality: Origins and outcomes. $J$ Pers Soc Psychol. 2000;78:122-135.

13. van den Heuvel M, Chen Y, Abdullah K, Maguire JL, Parkin PC, Birken CS. The concurrent and longitudinal association of temperament and nutritional risk factors in early childhood. Pediatr Obes. 12;12:431-438.

14. Abdullah K, Lebovic G, Birken CS, Maguire JL, Jenkins J, Parkin PC. Association between temperament and nutrition in pre-school children. Ann Pediatr Child Health. 2015;3:1088.

15. Leung CYY, Lumeng JC, Kaciroti NA, Chen YP, Rosenblum K, Miller AL. Surgency and negative affectivity, but not effortful control, are uniquely associated with obesogenic eating behaviors among low-income preschoolers. Appetite. 2014;78:139-146.

16. Vollrath ME, Hampson SE, Júliússon PB. Children and eating. Personality and gender are associated with obesogenic food consumption and overweight in 6- to 12-year olds. Appetite. 2012;58:1113-1117.

17. Vollrath ME, Stene-Larsen K, Tonstadt S, Rothbart MK, Hampson SE. Associations between temperament at age 1.5 years and obesogenic diet at ages 3 and 7 years. J Dev Behav Pediatr. 2012;33:721-727.

18. Vollrath ME, Tonstadt S, Rothbart MK, Hampson SE. Infant temperament is associated with potentially obesogenic diet at 18 months. Int J Pediatr Obes. 2011;6:e408-e414.

19. Riggs N, Chou CP, Spruijt-Metz D, Pentz MA. Executive cognitive function as a correlate and predictor of child food intake and physical activity. Child Neuropsychol. 2010;16:279-292.

20. Riggs NR, Spruijt-Metz D, Sakuma KL, Chou CP, Pentz MA. Executive cognitive function and food intake in children. J Nutr Educ Behav. 2010;42:398-403.

21. Tate EB, Unger JB, Chou CP, Spruijt-Metz D, Pentz MA, Riggs NR. Children's executive function and high-calorie, low-nutrient food intake: mediating effects of child-perceived adult fast food intake. Health Educ Behav. 2015;42:163-170.

22. Skogheim TS, Vollrath ME. Associations of child temperament with child overweight and breakfast habits: A population study in five-year-olds. Nutrients. 2015;7:10116-10128.

23. Cloninger CR, Zwir I. What is the natural measurement unit of temperament: single traits or profiles? Philos Trans R Soc Lond B Biol Sci. 2018;373:20170163.

24. van den Akker AL, Deković M, Prinzie P, Asscher JJ. Toddlers' temperament profiles: stability and relations to negative and positive parenting. J Abnorm Child Psychol. 2010;38:485-495.

25. Beekman C, Neiderhiser JM, Buss KA, et al. The development of early profiles of temperament: Characterization, continuity, and etiology. Child Dev. 2015;86:1794-1811.

26. Gartstein MA, Prokasky A, Bell MA, et al. Latent profile and cluster analysis of infant temperament: comparisons across person-centered approaches. Dev Psychol. 2017;53:18111825.

27. Prokasky A, Rudasill K, Molfese VJ, Putnam S, Gartstein M, Rothbart M. Identifying child temperament types using cluster analysis in three samples. J Res Pers. 2017;67:190-201.

28. Zwir I, Arnedo J, Del-Val C, et al. Uncovering the complex genetics of human temperament. Mol Psychiatry. 2018;Oct 2 doi: 10.1038/s41380-018-0263-6 [Epub ahead of print].

29. Anzman-Frasca S, Ventura AK, Ehrenberg S, Myers KP. Promoting healthy food preferences from the start: a narrative review of food preference learning from the prenatal period through early childhood. Obes Rev. 2018;19:576-604.

30. McClowry SG, Rodriguez ET, Koslowitz R. Temperament-based intervention: Re-examining goodness of fit. Eur J Dev Sci. 2008;2:120-135.

31. Belsky J, Pluess M. Beyond diathesis stress: differential susceptibility to environmental influences. Psychol Bull. 2009;135:885-908. 
32. Anzman-Frasca S, Stifter CA, Paul IM, Birch LL. Negative temperament as a moderator of intervention effects in infancy: testing a differential susceptibility model. Prev Sci. 2014;15:643-653.

33. Holley CE, Farrow C, Haycraft E. Investigating the role of parent and child characteristics in healthy eating intervention outcomes. Appetite. 2016;105:291-297.

34. Simell O, Niinikoski H, Rönnemaa T, et al. Cohort Profile: the STRIP Study (Special Turku Coronary Risk Factor Intervention Project), an Infancy-onset Dietary and Life-style Intervention Trial. Int J Epidemiol. 2009;38:650-655.

35. Niinikoski H, K P, Ala-Korpela $\mathrm{M}$, et al. Effect of repeated dietary counseling on serum lipoproteins from infancy to adulthood. Pediatrics. 2012(129):e704-e713.

36. Oranta O, Pahkala K, Ruottinen S, et al. Infancy-onset dietary counseling of low-saturated-fat diet improves insulin sensitivity in healthy adolescents 15-20 years of age: the Special Turku Coronary Risk Factor Intervention Project (STRIP) study. Diab Care. 2013;36:2952-2959.

37. Pahkala K, Hietalampi H, Laitinen TT, et al. Ideal cardiovascular health in adolescence: effect of lifestyle intervention and association with vascular intima-media thickness and elasticity (the Special Turku Coronary Risk Factor Intervention Project for Children [STRIP] study). Circulation. 2013;127:2088-2096.

38. McDevitt SC, Carey WB, Scottsdale AZ. Manual for the behavioral style questionnaire. In. Behavioral-Developmental Initiatives1996.

39. Fullard W, McDevitt SC, Carey WB. Assessing temperament in one- to three-year-old children. J Pediatr Psychol. 1984;9:205-217.

40. Sayal K, Heron J, Maughan B, Rowe R, Ramchandani P. Infant temperament and childhood psychiatric disorder: Longitudinal study. Child Care Health Dev. 2014;40:292-297.

41. Healy BT. Autonomic nervous system correlates of temperament. Infant Behav Dev. 1989;12:289-304.

42. Lo $\mathrm{Y}$, Mendell N, Rubin D. Testing the number of components in a normal mixture. Biometrika. 2001;88:767-778.

43. Vuong QHE, 307-333. Likelihood ratio tests for model selection and non-nested hypotheses. Econometrica: Journal of the Econometric Society. 1989;2:307-333.

44. Coppock JH, Ridolfi DR, Hayes JF, St Paul M, Wilfley DE. Current approaches to the management of pediatric overweight and obesity. Curr Treat Options Cardiovasc Med. 2014;16:343.

45. Nettleton JA, Hivert MF, Lemaitre RN, et al. Meta-analysis investigating associations between healthy diet and fasting glucose and insulin levels and modification by loci associated with glucose homeostasis in data from 15 cohorts. Am J Epidemiol. 2013;177:103115.

46. Matthews LA, Rovio SP, Jaakkola JM, et al. Longitudinal effect of 20-year infancy-onset dietary intervention on food consumption and nutrient intake: The randomized controlled STRIP study. Eur J Clin Nutr. 2018;41:2236-2244.

47. US Department of Health and Human Services; US Department of Agriculture. 2015-2020 Dietary Guidelines for Americans Washington, DC2015.

48. Stifter CA, Anzman-Frasca S, Birch LL, Voegtline K. Parent use of food to soothe infant/toddler distress and child weight status. An exploratory study. Appetite. 2011;57:693699.

49. Spielberger CD. State-Trait Anxiety Inventory: Bibliography (2nd ed.). Palo Alto, CA: Consulting Psychologists Press;1989.

50. Bates D, Maechler M, Bolker B, Walker S. Fitting linear mixed-effects models using Ime4 Journal of Statistical Software. 2015;67:1-48.

51. Kuznetsova A, Brockhoff PB, Christensen RH. ImerTest package: Tests in linear mixed effects models. Journal of Statistical Software. 2017;82:1-26. 
52. Tate AD, Trofholz A, Rudasill KM, Neumark-Sztainer D, Berge JM. Does child temperament modify the overweight risk associated with parent feeding behaviors and child eating behaviors?: An exploratory study. Appetite. 2016;101:178-183.

53. Lumeng JC, Miller AL, Horodynski MA, et al. Improving self-regulation for obesity prevention in Head Start: A randomized controlled trial. Pediatrics 2017;139:e20162047.

54. Fildes A, van Jaarsveld CHM, Cooke L, Wardle J, Llewellyn $\mathrm{CH}$. Common genetic architecture underlying young children's food fussiness and liking for vegetables and fruit. Am J Clin Nutr. 2016;103:1099-1104.

55. Laitinen TT, Nuotio J, Juonala $M$, et al. Success in achieving the targets of the 20-year infancy-onset dietary intervention: Association with insulin sensitivity and serum lipids. Diab Care. 2018;41:2236-2244.

56. Porges SW, Furman SA. The early development of the autonomic nervous system provides a neural platform for social behavior: A polyvagal perspective. Infant Child Dev. 2011;20:106118.

57. Chong SY, Chittleborough CR, Gregory T, Lynch JW, Smithers LG. How many infants are temperamentally difficult? Comparing norms from the Revised Infant Temperament Questionnaire to a population sample of UK infants. Infant Behav Dev. 2015;40:20-28.

Table 1. Descripton of the temperament traits.

\begin{tabular}{ll}
\hline Trait & Description of a high score \\
\hline Activity & Highly active; high amount of motor movement, restlesness \\
Rhythmicity & Irregular rhythms, eg. irregular eating and sleeping \\
Approach & Negative reaction to new persons or unfamiliar situations, withdrawal \\
Adaptability & Slow adaptability, takes long to adjust to change or transition \\
Intensity & Strong and long-lasting emotional reactions (eg, crying, screaming) \\
Mood & Negative mood, high amount of fussy or sad mood; complains a lot \\
Persistence & Low persistence; gives up quickly when facing obstacles or difficult tasks \\
Distractibility & Is easily distracted by external events \\
Sensory threshold & High sensitivity to external stimuli (eg, suffers from noises and heat) \\
\hline
\end{tabular}

Modified from Thomas, A. and S. Chess, Temperament and development. 1977,

New York: Brunner/Mazel. 
Table 2. Information criteria for the latent profile analysis

\begin{tabular}{|c|c|c|c|c|c|c|c|c|c|}
\hline $\begin{array}{l}\text { No. of } \\
\text { groups }\end{array}$ & $\begin{array}{l}\text { No.of } \\
\text { para- } \\
\text { meters }\end{array}$ & $\begin{array}{l}\text { Likelihood } \\
\text { ratio (LL) }\end{array}$ & $\begin{array}{l}\text { Bayesian } \\
\text { information } \\
\text { criteria } \\
\text { (BIC) }\end{array}$ & $\begin{array}{l}\text { Adjusted } \\
\text { Bayesian } \\
\text { information } \\
\text { criteria } \\
\text { (aBIC) }\end{array}$ & $\begin{array}{l}\text { Akaike's } \\
\text { information } \\
\text { criteria } \\
\text { (AIC) }\end{array}$ & $\begin{array}{l}\text { Corrected } \\
\text { AIC } \\
(\text { AICC) }\end{array}$ & $\begin{array}{l}\text { Vuong-Lo- } \\
\text { Mendell- } \\
\text { Rubin LRT } \\
\text { p-value }\end{array}$ & $\begin{array}{l}\text { Adjusted } \\
\text { LRT p- } \\
\text { value }\end{array}$ & Entropy \\
\hline 1 & 18 & -7347.63 & 14813.64 & 14756.49 & 14731.27 & 14732.25 & & & \\
\hline 2 & 28 & -6984.63 & 14153.40 & 14064.49 & 14025.26 & 14027.62 & $<.001$ & $<.001$ & 0.73 \\
\hline 3 & 38 & -6890.84 & 14031.59 & 13910.93 & 13857.69 & 13862.05 & $<.01$ & $<.01$ & 0.73 \\
\hline 4 & 48 & -6840.71 & 13997.09 & 13844.68 & 13777.42 & 13784.45 & 0.38 & 0.39 & 0.69 \\
\hline 5 & 58 & -6802.23 & 13985.89 & 13801.72 & 13720.45 & 13730.84 & 0.15 & 0.15 & 0.74 \\
\hline 6 & 68 & -6772.43 & 13992.06 & 13776.14 & 13680.86 & 13695.32 & 0.12 & 0.12 & 0.67 \\
\hline 7 & 78 & -6755.99 & 14024.94 & 13777.27 & 13667.97 & 13687.26 & 0.50 & 0.51 & 0.68 \\
\hline 8 & 88 & -6737.33 & 14053.39 & 13773.96 & 13650.66 & 13675.56 & 0.55 & 0.55 & 0.68 \\
\hline 9 & 98 & -6725.73 & 14095.95 & 13784.77 & 13647.46 & 13678.80 & 0.87 & 0.87 & 0.66 \\
\hline
\end{tabular}

Note. No.=Number. 
Table 3. The final growth curve model predicting the diet score.

\begin{tabular}{lrrr}
\hline Predictors in the model $^{\mathrm{a}}$ & $\mathrm{B}$ & \multicolumn{1}{l}{ SE } & \multicolumn{1}{c}{$P$} \\
\hline Neutral temperament (ref. negative/low regulation) & 0.85 & 0.33 & 0.01 \\
Positive/high regulation temperament (ref. negative/low regulation) & 0.94 & 0.38 & 0.01 \\
Dietary intervention group (ref. control group) & 2.31 & 0.25 & $<.001$ \\
Male (ref. female) & -0.21 & 0.28 & 0.45 \\
Linear age & 0.09 & 0.16 & 0.58 \\
Quadratic age & 0.39 & 0.08 & $<.001$ \\
Dietary intervention $\times$ linear age & -0.33 & 0.16 & 0.04 \\
Male $\times$ linear age & -0.39 & 0.16 & 0.01 \\
Male $\times$ quadratic age & -0.30 & 0.11 & 0.01 \\
\hline
\end{tabular}

Note. ref.=the reference group; $\mathrm{B}=$ standardized beta coefficient; $\mathrm{SE}=$ standard error;

The original model with all tested main effects and interactions is in Supplement table 3.

aAdjusted for parental educational level, parental anxiety, and participants' body-mass index. 
Table 4. Standardized beta coefficients of temperament traits at 2 years of age predicting the diet score level over 20 years.

\begin{tabular}{lrr}
\hline & $B$ & \multicolumn{1}{c}{$\mathrm{p}$} \\
\hline High activity & -0.25 & 0.059 \\
Irregularity & -0.56 & $<0.001$ \\
Withdrawal & -0.06 & 0.645 \\
Slow adaptibility & -0.18 & 0.164 \\
High intensity & -0.29 & 0.027 \\
Negative mood & -0.16 & 0.214 \\
Low persistence & -0.19 & 0.129 \\
High distractability & -0.10 & 0.417 \\
Low sensory threshold & 0.00 & 0.971 \\
\hline
\end{tabular}

Note. There were no significant AgexTemperament trait-interactions predicting the diet score. 


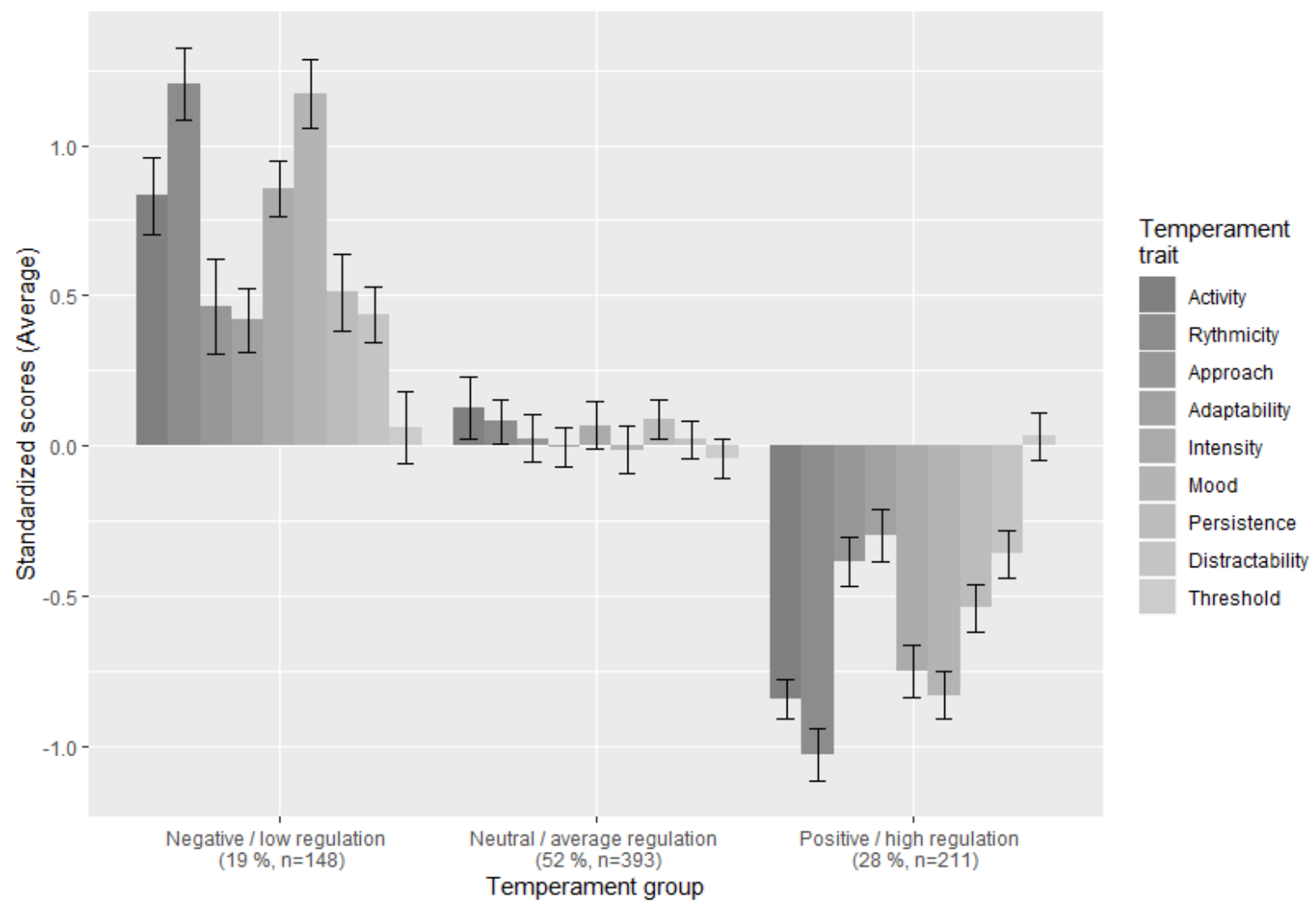

Figure 1. Standardized mean values of the temperament traits in the temperament groups obtained by latent profile analysis. 


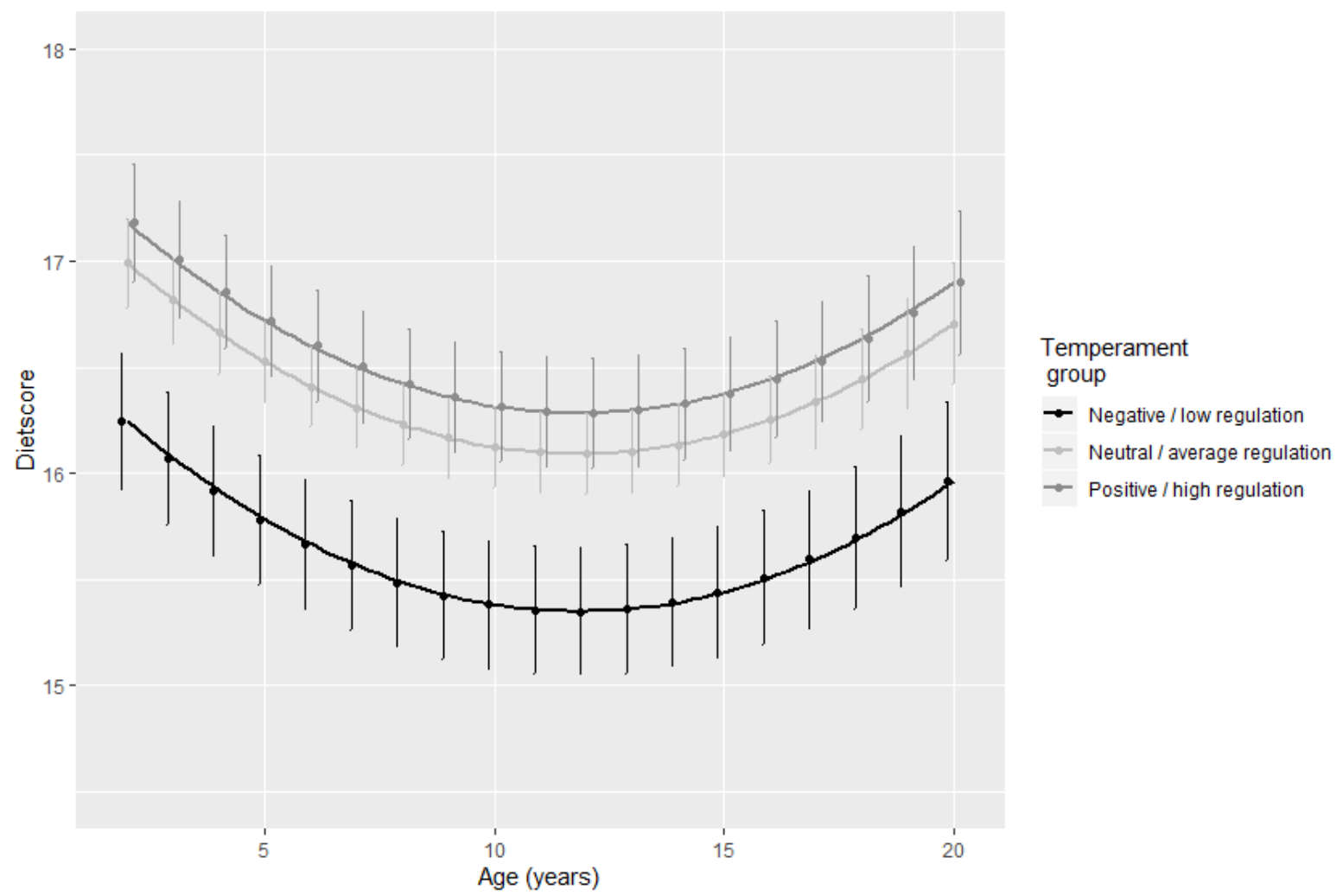

Figure 2. Predicted mean values of the diet score from 2 years of age until 20 years of age in children belonging to the different temperament groups.

Note: A higher diet score value means a healthier overall diet. 